\title{
PSYCHE
}

VOL. XXXIV.

OCTOBER 1927

No. 5

\section{THE MALE GENITAL TUBE OF SOME OF THE SPECIES OF THE GENUS SCYMNUS (COLEOPTERA, FAM. COCCINELLID $\approx)^{1}$}

\section{By J. W. WIIsON.}

The genus Scymnus is one of the largest in the family Coccinellidæ and one in which the species are very hard to determine on account of their remarkable uniformity in appearance. The adult beetles are small, ranging from $1.1 \mathrm{~mm}$. to approximately $3 \mathrm{~mm}$. in length, rounded to oblong-oval in shape, pubescent, with six ventral abdominal segments showing, and the legs free. The color markings are quite constant, "Color characters have their utility in the separation of species of Scymnus, but some care and no little experience is required in their use" (Horn 1895). Casey (1899) in his revision of the Coccinellidæ used color to a great extent in the separation of the species. The prosternal carinæ and the abdominal plates or metacoxal lines are other characters which are very useful in this group. The secondary sexual characters of the male are quite distinct in most of the species, but have been mentioned in the description of very few of the species.

Leng (1920) lists one hundred and nineteen species from North America, sixty-five of which were described by Casey, seventeen by Leconte, fourteen by Horn, ten by Mulsant, four by Fall, three by Crotch, three by Melsheimer, one by Blatchley, and one by Say. Casey believed that the number of species would be increased in the future instead of decreased. Nothing has been done with the genus Scymnus since Casey's "Revision of the American Coccinellidæ," except the description of four species by Fall and one by Blatchley.

${ }^{1}$ Contributions from the Entomological Laboratory of the Bussey Institution, Harvard University, No. 276 
The genitalia of the male are usually accepted as being the final criteria for species about whose validity there is any doubt. A study of the genitalia will also show the degree of relationship between species in a group. With these facts in view the present study was undertaken in the hope that significant variations might be found in the œdagus of species having only slight external differences.

Since it is very easy to make erroneous determinations in this group, the present paper includes only that material which was compared with the types. All the species were described by Lecont except five, and the specimens were carefully compared with the Leconte types in the Museum of Comparative Zoology at Cambridge. The other five species were identified by Leconte, and were included in his collection. As my identifications agree with his, I felt safe in using these species in my investigation.

I wish here to thank Mr. Nathan Banks for his kind generosity in allowing me the use of the collection in the Museum of Comparative Zoology. I am also greatly indebted to Mr. C. A. Frost who loaned me his collection with permission to dissect any of the specimens which I might see fit to use for such purposes.

In a previous paper (Wilson 1926) the structure of the Coccinellid œdagus was described in detail. The general structure of the œdagus of Scymnus is similar to that of other Coccinellids. The basal lobe surrounds the median lobe and is very variable in shape. In such forms as Scymnus americanus Muls., the basal lobe is quite similar to that of Brachyacantha ursina Fab., which is one of the simplest of the forms described in that paper.

The material here presented seems to fall naturally into four groups, and if a study of the whole genus could be made it would probably be possible to separate the genus into several groups, each group showing some relation to the other groups.

The œdagus of quadritoeniatus Lec. is particularly interesting because the proximal end of the median lobe is not flattened and expanded as in the other species. The median lobe is also 
less chitinized and is looped around the median strut. The lateral lobes are large as compared with the basal lobe.

In the second group which consists of americanus Muls., punctatus Mels., cervicalis Muls., and terminatus Say, the proximal end of the median lobe shows specific variations. In fact the proximal end of the median lobe, and the basal lobe, are the structures which are most variable in all the groups.

The œdagus of nanus Lec., semiruber Lec., cinctus Lec., and hemorrhous Lec., are larger than the odagi of the second group. All of the drawings were made at a magnification of about 115 diameters, except in the case of americanus and puncticollis, which were magnified about 85 diameters. The proximal end of the median lobe in nanus and semiruber are somewhat alike, and resemble that of terminatus to a certain extent. The same area in cinctus and hoemorrhous has in addition a small area, in the upper portion of which are found alternate bands of thick and thin chitin. The basal lobe is also much modified in cinctus and homorrhous. It extends through the basal piece, and beyond it anteriorily, for a short distance. Possibly if more material were available, there would be two groups instead of one, nanus and semiruber belonging to one, and cinctus and homorrhous to the other.

The basal lobe of puncticollis Lec., consobrinus Lec., and tenebrosus Muls., is much expanded, and very much larger than the lateral lobes. The shape of the basal lobe is also rather complicated in structure and projects beyond the basal piece anteriorily. At the distal end of the median lobe there are several stiff, bristle-like projections which point forward. There are also specific differences in the proximal end of the median lobe.

If we consider the genitalia of consobrinus and tenebrosus it would appear that these species are closely related, while in the key they fall into separate groups, and their relation would never be suspected. The genitalia of the Coccinellidæ are rarely extruded and are rather difficult to dissect out, for this reason they will never be of any value as key characters, as in the case of other groups. However, further study of the genitalia of the genus Scymnus will undoubtedly show the relationship between the various species. 


\section{Literature Cited.}

Casey, Thomas L. 1899. A Revision of the American Coccinellidæ, Journ. New York Ent. Soc., VII, 138-160

Crotch, G. R. 1874. Revision of the Coleoptera Family Coccinellidæ, London 1-311

Horn, G. H. 1895. Studies in Coccinellidæ, Tran. American Ent. Soc., XXII, 81-114

Leng, Charles W. 1920. Catalogue of the Coleoptera of America North of Mexico,

Sharp, D. and Muir, F. 1912. The Comparative Anatomy of the Male Genital Tube in Coleoptera. Tran. Ent. Soc. London, 477-639

\section{Abbreviations}

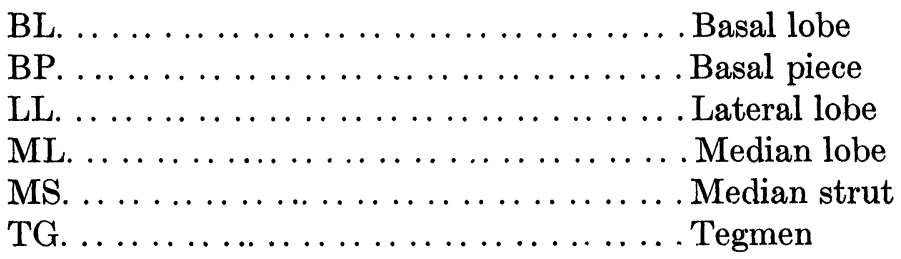

\section{Explanation of Plate VI.}

Fig. 1 Scymnus quadritcniatus Lec.

Fig. 2 Scymnus americanus Muls.

Fig. 3 Scymnus punctatus Mels.

Fig. 4 Scymnus cervicalis Muls.

Fig. 5 Scymnus terminatus Say

Fig. 6 Scymnus nanus Lec.

Fig. 7 Scymnus semiruber Lec.

Fig. 8 Scymnus cinctus Lec.

Fig. 9 Scymnus hcomorrhous Lec.

Fig. 10 Scymnus puncticollis Lec.

Fig. 11 Scymnus consobrinus Lec.

Fig. 12 Scymnus tenebrosus Muls. 


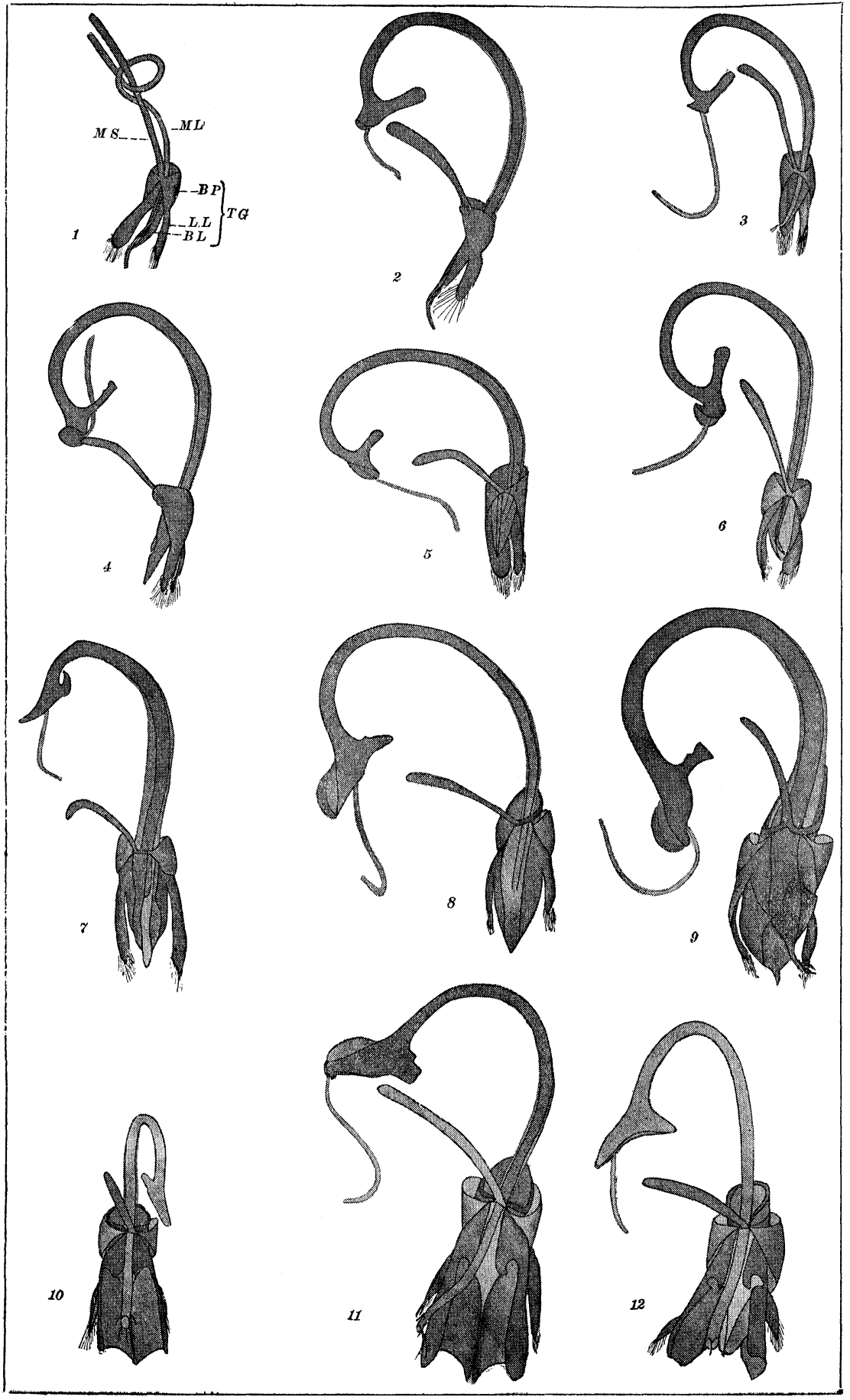

WILSON - MALE GENITAL TUBE OF SoymNUS 

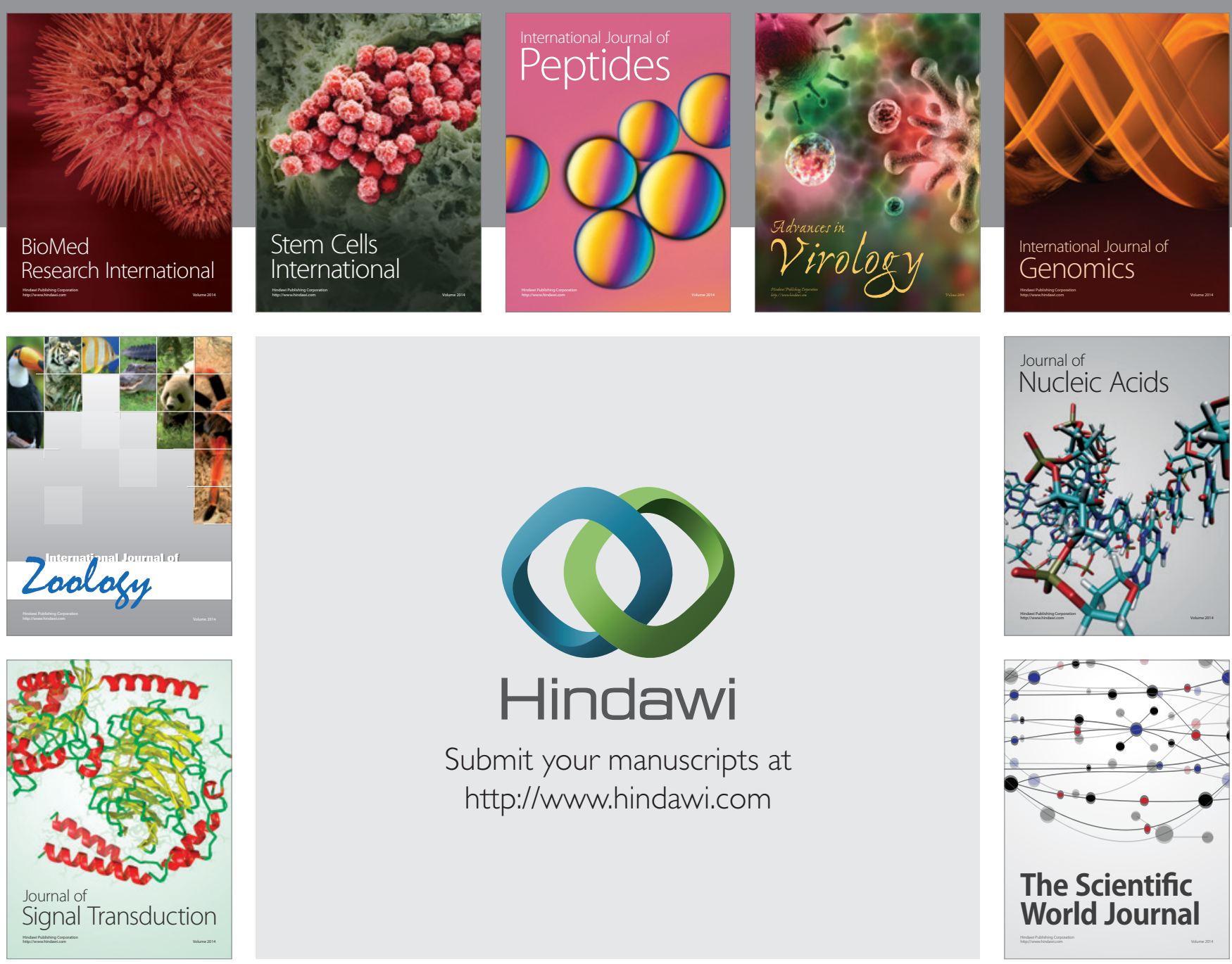

Submit your manuscripts at

http://www.hindawi.com
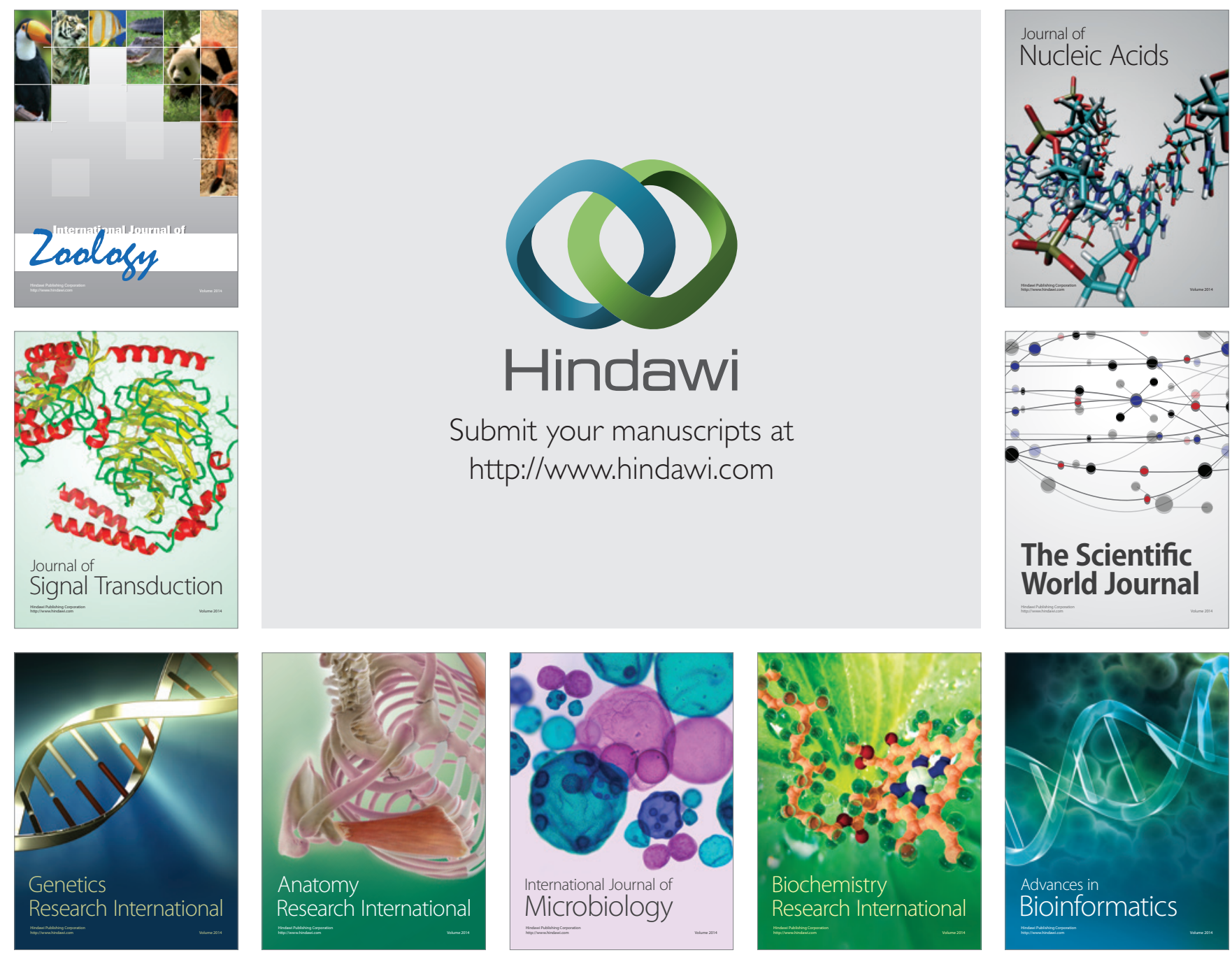

The Scientific World Journal
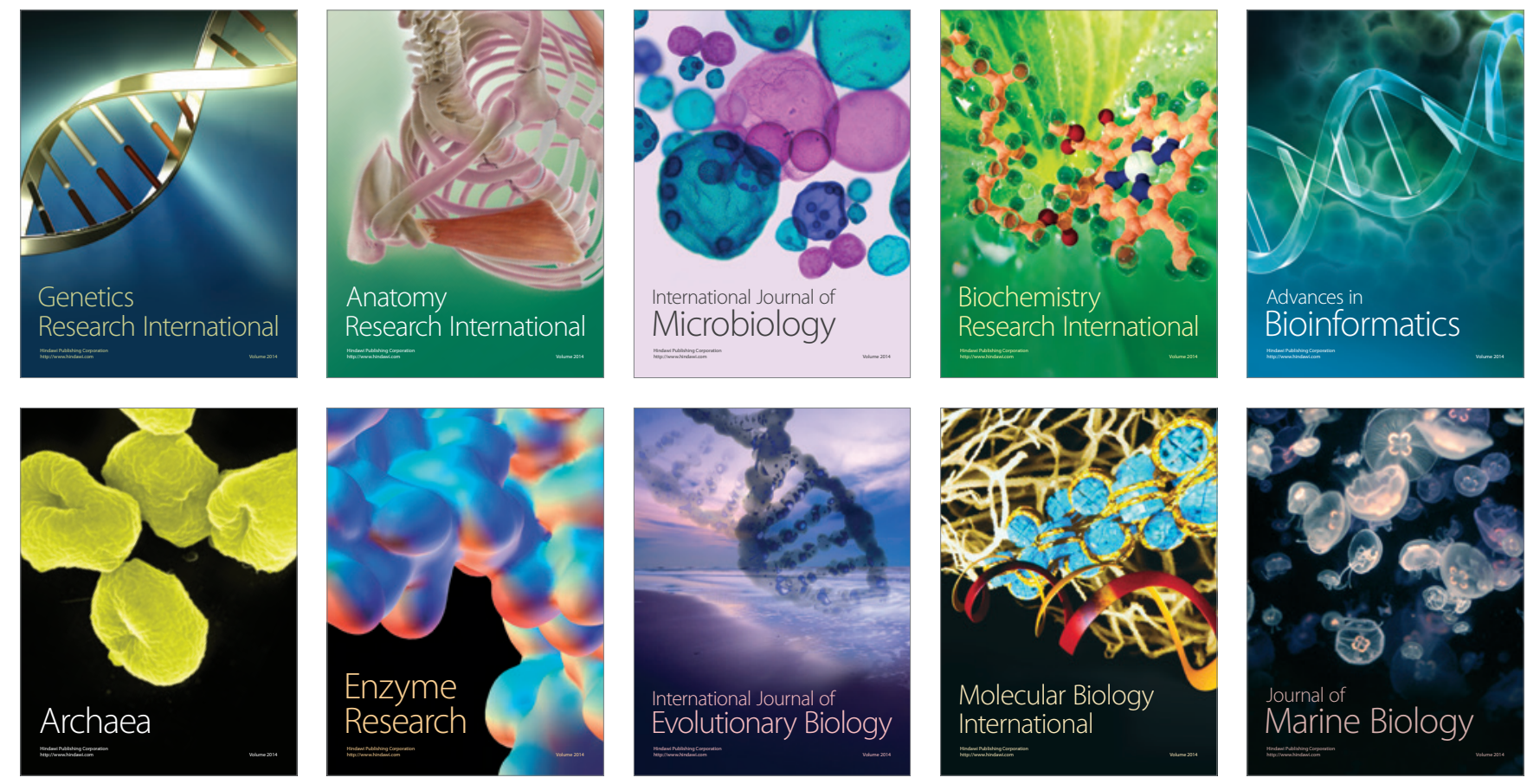